\title{
A FILOSOFIA CHINESA PUBLICADA NO BRASIL NOS SÉCULOS XX E XXI
}

John Breno Rodrigues de Sousa ${ }^{1}$

\section{RESUMO}

O presente texto se propõe a apresentar um estudo quantitativo das obras de filosofia chinesa publicadas no Brasil durante os séculos XX e XXI, a partir da realização de uma pesquisa historiográfica, com ênfase em autores como Confúcio, Sunzi e Laozi. Para a elaboração do estudo, utilizou-se uma catalogação das publicações de filosofia chinesa feita no decorrer de um ano em um projeto de Iniciação Científica. A pesquisa se deu por meio dos bancos de dados das bibliotecas e acervos públicos e privados, tal catalogação partiu da metodologia de D’Hulst (2001) que procura, tendo em vista o trabalho de tradução, responder às seguintes questões: “Quem? O quê? Onde? Quem ajuda? Por quê? De que forma? Quando? Para quem?”. Foram encontradas duzentas e vinte e cinco (225) publicações no período citado: um trabalho realizado por cento e quatorze (114) casas editoriais e se verificou que a frequência das publicações seguiu as tendências do mercado editorial brasileiro. O artigo divide-se em três seções principais, a primeira seção, intitulada "A filosofia chinesa", subdivide-se em outras cinco subseções: em "os três ensinamentos", explica-se o conceito que norteou o escopo da pesquisa; a seguir, apresenta-se "uma breve contextualização da História chinesa", a qual é preservada e exaltada pelos filósofos chineses; em seguida, serão fornecidas breves introduções sobre a biografia dos autores citados, suas principais ideias e objetivos, tal como o contexto de sua produção. A partir desse ponto, a segunda seção do artigo descreverá o início “[d]a ponte tradutológica entre a China e o ocidente", portanto, se trata da História da tradução dos cânones chineses; e, por fim, será apresentado os dados do catálogo de obras de "filosofia chinesa publicadas no Brasil nos séculos XX e XXI". PALAVRAS-CHAVE:FilosofiaChinesa; Confucionismo; Taoismo; AArte da Guerra; Editoração Brasileira

1 Bacharel em Letras com habilitação português-chinês pela Faculdade de Filosofia, Letras e Ciências Humanas (FFLCH) da Universidade de São Paulo (USP). O presente artigo foi fruto de um trabalho de Iniciação Científica desenvolvido no Departamento de Jornalismo e Editoração da Escola de Comunicações e Artes da USP sob orientação do prof. Dr. Thiago Mio Salla. E-mail para contato: john.sousa@usp.br 


\section{A filosofia chinesa}

\subsection{Os três ensinamentos}

O tema da atual pesquisa, "A filosofia chinesa publicada no Brasil nos séculos XX e XXI", enfrenta, primeiramente, uma problemática metodológica: qual o alcance do termo "filosofia", sendo que há uma "tendência prevalente na China antiga, de tornar indistintas as linhas de demarcação entre política, ética e religião" (POCESKI, 2013, p. 84)? Inclusive em termos contemporâneos ocidentais a linha de distinção entre filosofia e religião é tênue e gera uma extensa bibliografia. Dessa forma, quando se observa a sociedade chinesa, na qual as concepções dos limites entre as duas áreas muitas vezes se confundem, torna-se essencial, antes de tudo, que se entenda essa relação.

Se se pesquisar sobre publicações de filosofia chinesa nos bancos de dados bibliográficos, não é raro encontrar títulos que tratam sobre religiões. Isso ocorre porque as tradições milenares da China, embora originalmente fossem ideias de como organizar o indivíduo na sociedade, no decorrer da História ganharam leituras religiosas e, por vezes, subtradições. Tal fato gerou um problema metodológico para a pesquisa: o que deve ser entendido, aqui, como filosofia chinesa nessa pesquisa? Qual a intersecção entre religião e filosofia no que toca à China antiga? Quais "obras de religião" devem ser observadas, quais não e por quê? Não é o foco, porém, realizar uma discussão profunda sobre os conceitos de filosofia e religião, mas uma dissertação histórica, sobre a compreensão chinesa de suas tradições de pensamento, para fins metodológicos. Com isso em vista, pode-se iniciar uma pequena dissertação sobre o principal objeto de estudo do presente trabalho, isto é, o pensamento chinês.

A China possui três tradições dominantes, que influenciaram suas crenças e valores e que se sustentaram até os dias atuais. Essas tradições são denominadas pelos chineses como os "três ensinamentos", "três tradições" ou "três religiões" (traduções possíveis para o vocábulo chinês), termo que engloba o budismo, confucionismo ${ }^{2}$ e taoismo, sendo que cada uma delas tem uma história longa e importante na China e interage com as outras duas tradições. A partir dessa interação entre as tradições, não havia uma delimitação conceitual de "filosofia", "religião", "ética" e "política". Havia os "três ensinamentos", e eles, com base na História e rituais tradicionais chineses, influenciavam esses diversos aspectos do cotidiano.

2 Agradeço a Amilton Reis que me alertou de que “Apesar de registrar 'confucionismo', os dicionários dão preferência a confucianismo, que deriva do adjetivo 'confuciano', pelo mesmo processo regular observado em Lutero $>$ luterano > luteranismo; nas formas derivadas do nome, como Mao > maoísmo e Tao > taoismo, o sufixo -ismo liga-se diretamente à raiz; o -n- intercalado em 'confucionismo' não tem, portanto, justificativa do ponto de vista morfológico." Entretanto, por considerar que o termo "confucionismo" tem uma forte consolidação na língua portuguesa e é o termo encontrado nas bases de dados e nas obras pesquisadas, optou-se, neste artigo, pelo uso deste termo. 
A expressão san-jiao (三教) é entendida por alguns dos modernos estudiosos chineses como "três religiões", embora a maioria deles interprete como "três ensinamentos" ou "três tradições". Sob a ótica dos pilares do saber/cultura da China, podemos considerá-los como ensinamentos filosóficos e religiosos. [...] Durante sua longa história, cada um dos três ensinamentos filosóficos e religiosos desenvolveu sofisticados sistemas de doutrinas, cânones de escritos sagrados, injunções morais sobre conduta cotidiana, instituições distintas e uma diversidade de cerimônias e práticas rituais. Além disso, nos casos do budismo e do taoismo, encontramos ordens monásticas bem desenvolvidas abertas a homens e mulheres (POCESKI, 2013, p. 8).

No que se refere às publicações sobre o pensamento chinês no Brasil, a maioria delas tratam desses "três ensinamentos" (desde traduções e comentários até releituras ou projetos inspirados nos cânones dessas tradições). E, por isso, o conceito de "três ensinamentos" foi utilizado, neste trabalho, para definir o escopo de filosofia chinesa, quando houve dúvida se se tratava de uma obra filosófica ou religiosa. E.g., durante a catalogação foram encontradas obras que pareciam de ter um conteúdo espiritualista, no entanto o tema era o taoismo. Em virtude do taoismo ser uma tradição que compõe um dos "três ensinamentos", e estes tenderem a mesclar, oqueo ocidentecontemporâneo chama dereligião efilosofia, aquelas obras foramaceitasno catálogo.

Entretanto, deve-se pontuar que apesar de o budismo pertencer aos "três ensinamentos", trata-se de uma tradição de origem não-chinesa (vinda da Índia). E a catalogação das obras desse segmento exigiria outra metodologia para diferenciar o "conteúdo religioso" do "conteúdo filosófico", pois as produções referentes ao budismo tendem a não apenas ser de caráter religioso, como também possuem uma quantidade alta de publicações, o que requisitaria um tempo mais longo de pesquisa e isso dificultaria muito essa primeira fase.

Posto isso, no catálogo registrou-se as obras que compõem os "três ensinamentos", aquelas que tratavam do confucionismo e do taoismo, excluindo o budismo. Contudo, adicionou-se ao catálogo a obra $A$ arte da guerra, de Sunzi, por ela ter uma presença forte no mercado editorial brasileiro, como será mostrado, e seu autor pertence ao mesmo período de Confúcio e Laozi, fundadores das duas tradições selecionadas.

Enfatiza-se ainda que na concepção chinesa, na qual os "três ensinamentos" são concomitantes e complementares, o confucionismo serve, principalmente, para reger a ordem externa de relações entre os homens, enquanto o taoismo e o budismo servem, sobretudo, para a ordem interna, a espiritual. É um fato que mesmo sendo uma concepção filosófica, o confucionismo ganhou um status religioso e de filosofia de Estado, e o taoismo foi dividido desde cedo em duas vertentes: o taoismo filosófico e o religioso. 


\title{
1.2 Breve contextualização da História chinesa
}

Graças ao fato de a História da China ser preservada por suas tradições cabe aqui uma pequena contextualização. Chang (2007) disserta sobre a História da China antiga que passa pela Cosmogonia (o mito da criação), os heróis e os reis lendários (os Três Soberanos e os Cinco Imperadores): O mito de criação do "País do Meio"33 conta que o mundo era um ovo opaco, e Pángǔ (盘古) nasceu dentro dele; por dezoito mil anos este ovo foi chocado com o Yīn (阴), Yáng (阳) e Pángǔ dentro dele, até que ele se choca: do Yáng, a parte clara, surge o Céu; do Yīn, a parte escura, nasce a Terra. Todos os dias Pángǔ se tornava mais alto, o Céu ia mais para o alto, e a Terra mais para baixo. Quando Pángǔ morreu

\begin{abstract}
a sua respiração se tornou os ventos e as nuvens; sua voz, o trovão; seu olho esquerdo, o sol; seu olho direito, a lua; de seus quatro membros e cinco torsos, os quatro polos e as cinco montanhas; seu sangue, os rios; seus tendões, as características geográficas; seus músculos, os solos no campo; seu cabelo e barba, estrelas e planetas; sua pele e pelos, a grama e as árvores; seus dentes e ossos, bronzes e jades; sua essência e medula, pérolas e joias; seu suor, a chuva e os lagos; e os vários vermes e seu corpo, tocados pelo vento, se tornaram os plebeus de cabelos pretos. (Ma Su, s.d., apud CHANG, 2007, p. 66-67).
\end{abstract}

Depois do mito da criação, a cultura chinesa conta com os heróis dos quais, segundo Chang (2007), destacam-se Suìrén ( 燧人), inventor do fogo; Fúxī (伏羲), inventor do ritual de casamento e da caça; e Shénnóng (神农), inventor da agricultura e da medicina. Quanto a Fúxī, ele foi o criador de um "sistema de desenho místico" (CHANG, 1962, p. 2.), conhecido como os oito trigramas (八卦， bāguà), tais trigramas são significativos, de acordo com Chang (1962, p.2), não só por ser uma forma ancestral de chinês escrito (ainda não pictográfica), mas também por englobar um pensamento filosófico singular. A edição do Livro das Mutações $^{4}$ (易经, Yìjīng), com reunião dos trigramas, será atribuída a Confúcio. Suìrén, Fúxī e Shénnóng são tão importantes que eles recebem o título de Sān Huáng (三皇, “os Três Soberanos”) na História chinesa.

Após os Três Soberanos e as suas invenções que marcam a história humana (na China), Chang (2007) conta a história dos Cinco Imperadores (五帝, Wǔ Dì) e as marcas das instituições na China: o primeiro foi o Imperador Amarelo a quem é creditada a instituição de regras, calendários sofisticados e a escrita; o segundo imperador foi Zhuan Xu a quem é associada a separação do Céu e da Terra, assim o céu se tornou inacessível à maioria que não poderia contratar um "curandeiro tribal", marcando estratificação social e os mecanismos de acumulação da riqueza; e os últimos três imperadores são Yao, Shun e Yu, segundo a lenda, eles se tornaram imperadores não por

3 "País do Meio" [em mandarim 中国 (Zhōngguó)] é tradução literal do nome da China.

$4 \quad$ No Brasil, o título mais comum é I ching. 
Zi Yue: revista de graduação de estudos sinológicos. São Paulo: Portal de Revistas da USP, v. 1, n. 1, 2020.

hereditariedade, mas por suas virtudes, por isso serão exaltados por filósofos como Confúcio.

A história dinástica na China antiga começa com as chamadas "três dinastias": Xia, Shang e Zhou.

Este último período é marcado por uma confederação frágil de clãs que apoiavam um rei. A dinastia Zhou (1122-256 AEC) terá uma importância especial, pois foi neste período que viveram personalidades como Confúcio, Laozi e Sunzi. Ela foi responsável por criar uma estabilidade política de longa duração e que seria saudada como a grande era da Antiguidade a ser copiada, principalmente em relação aos seus primeiros reis.

Segundo Poceski (2013, p.16), os êxitos do início da Dinastia Zhou foi a existência de "governantes paradigmáticos, que estabeleceram um Estado estável e forte, com uma cultura florescente que, ao longo dos séculos foi celebrada como um modelo glorioso a ser seguido pelas gerações posteriores de governantes e autoridades chinesas." Todavia, com a perda do poder político da Dinastia Zhou e após ser saqueada em 771 AEC, a história da dinastia divide-se em dois períodos: A era da Primavera e Outono e a Era dos Estados Combatentes; na primeira com a fragmentação do poder político, os estados vassalos buscam cada vez mais poder, sendo o poder dos Zhou relegados a meras figuras decorativas, com uma autoridade ritual, mas sem poder real para mediar os conflitos "estaduais"; na segunda, os conflitos ficam ainda mais violentos e daí deriva seu nome, nessa era os estados já haviam desenvolvido instituições burocráticas e grandes exércitos. Nesse contexto de conflitos, surgiu um grande avanço econômico e tecnológico, além ser um período bem rico intelectualmente com a "formação" de várias escolas de pensamento que buscavam pensar e discutir ações para a crise. Por fim, em 221 AEC, o grande estado de Qin, conhecido por ser militarista e autoritário, consegue se sair vencedor e reunir a China num estado imperial.

\subsection{Confucionismo}

O confucionismo remete a Confúcio (551-479AEC), tradução em língua portuguesa do nome Kŏngfūž̌ (孔夫子), ou “Mestre Kong”, sendo Kong o nome do seu clã. Segundo Sinedino (CONFUCIO, 2012, p.15) o pai de Confúcio era um homem que descendia da nobreza da dinastia Shang, contudo, devido aos costumes sucessórios, não tinha posses, além de seu status de pessoa livre (garantido pelo sangue nobre numa era abertamente escravista) e seu acesso à educação. E Confúcio estava nas mesmas condições que seu pai, tendo que trabalhar como professor particular de Ritos (categoria que possuirá uma importância inigualável na ideologia confuciana e compreende a um misto de regras de etiqueta e de leis tradicionais seguidas pela aristocracia). Ele ficou famoso no estado de Lu onde tinha boas relações com a nobreza, tornando-se um funcionário do duque de Lu, mas teve uma breve carreira política fracassada por seus ideais legitimistas. Seus ideais se baseavam na legitimidade 
histórica da autoridade do duque de Lu, e Confúcio pregava contra nobres com títulos inferiores que exerciam mais poder que um nobre com título superior ${ }^{5}$, o que entrou em conflito com aristocratas do estado de Lu que de fato detinham o poder; por isso Confúcio partiu em exílio semivoluntário procurando serviço nas cortes dos estados vizinhos. Lembrando que nessa época (Era da Primavera e Outono da dinastia Zhou), a China passava por rápidas transformações e uma situação de guerra civil.

Confúcio morreu como um homem respeitado, deixando um legado de muitos discípulos, mas não viu em vida seu ideal ser posto em prática: ele acreditava que os homens capazes não deveriam assumir o governo ${ }^{6}$, mas deveriam se colocar à disposição das instituições já existentes, pois um rei cercado por homens éticos e competentes se tornaria um bom rei, sendo que tais homens capazes deveriam vir de todas as camadas sociais, que a educação deveria ser de todos, e todos deveriam ter a oportunidade de alcançar uma posição como funcionário público. Para o filósofo, primeiro seria necessário tentar colocar os ideais bons de governo em ação, caso não fosse possível, dever-se-iam elaborar obras de referência para os "homens nobres futuros”. De acordo com Poceski (2013, p. 52), “O objetivo principal de Confúcio era restabelecer o 'caminho eterno' (Tao), que foi revelado e seguido pelos antigos sábios, os quais reproduziam as normas e desígnios do Céu e traziam a harmonia perfeita entre Céu e a humanidade."

Para Confúcio, a criação da sociedade boa e harmoniosa tratava da codificação de costumes e práticas comuns, uma sociedade já caminharia melhor se o filho servisse ao pai; a mulher servisse ao marido, e o súdito servisse ao soberano, sendo que a outra parte deveria retribuir a servidão com benevolência. Tal ideia denominada de piedade filial seria correspondente a "dar ao outro o que é do outro", por exemplo, o pai deveria dar ao filho aquilo que é do filho: alimentação, vestuário, educação; e o filho por sua vez deveria retribuir ao pai aquilo que é do pai: respeito e obediência.

Por fim, é preciso esclarecer que o confucionismo se tornou uma "filosofia de estado" duas dinastias depois da Zhou, na chamada dinastia Han (206 AEC- 220 EC14), a "Escola dos Eruditos" ganha um status privilegiado passando a ser o estudo obrigatório nas escolas e o conteúdo das provas para concursos públicos até a dinastia Qing (1644-1911). Weber (2006, p. 171) afirma não existir na China uma

5 Observa-se que na época a China era uma "confederação" de clãs reunidos sob uma autoridade central (a daquele rei que fala com o Céu), mas a influência do rei enfraqueceu e em todos os estratos sociais houve disputas internas para conquistar mais poder. Talvez tal situação possa ser melhor compreendida se comparada com o Feudalismo europeu, no qual havia um rei e vassalos, imagine-se que a influência do rei tenha diminuído e que os vassalos começaram a guerrear entre si, um vassalo tomando território do outro vassalo. Ressalta-se ainda que Confúcio acreditava que as pessoas comuns, por mérito, poderiam subir de status, mas que dever-se-ia respeitar a legitimidade daqueles que estavam em cargos superiores. 6 Novamente, salienta-se que tal princípio confuciano se baseia na legitimidade, os reis possuiriam a legitimidade de estar em tais cargos, tentar tirar os reis de seus cargos seria um "golpe", todavia os reis poderiam perder a legitimidade de governar e, assim, poderiam ser substituídos.

$7 \quad$ Nome dado em chinês para a escola de pensamento confuciana. 
intelectualidade independente, sem a chancela do Estado, que consiga se opor à cultura confucionista, logo o confucionismo na China era a ética do "homem distinto". Confúcio tinha um conhecimento muito profundo das obras chinesas e deixou um legado de obras que, depois da chancela dele, o estado tornou obrigatórias em concursos públicos, assim "os cinco clássicos confucianos" são: o livro das canções (Shijing), uma antologia de versos da fase inicial da Dinastia Zhou durante os períodos primavera e Outono; o livro das mutações (Yijing), um manual de adivinhação desde a Dinastia Zhou, com acréscimos da Dinastia Han; o Livro dos Documentos (Shujing), uma coleção cronológica de discursos, proclamações e histórias acerca de antigos governantes dos períodos pré-Zhou e Zhou; os Anais de Primavera e Outono (Chunqiu), uma crônica do estado de Lu até a época de Confúcio; e os Três [textos sobre] Rituais (Sanli), discussões sobre rituais tradicionais e instituições governamentais, dos períodos dos Estados Combatentes e Han. Observa-se ainda a existência do Livro da Música (Yueling), o qual em certo momento foi conhecido como o sexto clássico, porém foi perdido antes do período Han (POCESKI, 2013, p. 47). $\mathrm{Na}$ Idade Média, foram adicionadas aos cânones confucianos obras que não foram escritas ou editadas por Confúcio, mas que tratavam sobre o seu pensamento, tais obras são denominadas os Quatro Livros, Sìshū (四书): “Os analectos de Confúcio", “Mêncio", “Grande Conhecimento" e "Doutrina no Meio".

\subsection{Taoismo}

Ao lado do confucionismo, o segundo ensinamento que influenciou o pensamento chinês por milênios foi o taoismo, termo que deriva de Tao (道, dào ${ }^{8}$ ) e significa "Caminho" ou "Curso" (POCESKI, 2013, p.76), mais especificamente dentre os seus significados inclui-se "a força impessoal criativa do universo que é perpétua e gera o ying e yang, a partir do que emergem as miríades das coisas". Observa-se que o Tao possui acepções diferentes a depender da tradição em que se insere e, no contexto confuciano, se baseava nos padrões adequados de comportamento humano, como os rituais e as ações do cotidiano, para que se sigam os desígnios do Céu; é um termo tão importante que também está presente no vocabulário budista. Poceski (2013, p. 77) compara que "o domínio fundamental do taoismo é o mundo da natureza, que engloba outras dimensões sobrenaturais ou transcendentais, em contraste com o principal objetivo do confucionismo, que era o contexto social".

Quando academicamente tentou-se estudar o taoismo, percebeu-se a diferença entre o taoismo dos mestres, ou o taoismo "filosófico”, um taoismo primitivo dos textos literários de Laozi e Zhuangzi, e um taoismo "religioso" posterior. Apesar da importância de Zhuangzi， Lăožr (老子), autor de Dàodéjīng (道德经), é visto como o fundador e o principal nome do taoismo. Laozi compartilha com Confúcio o fato 
de ser um shi, um membro da baixa nobreza que não possuía bens econômicos, mas possuía bens culturais e educacionais. Laozi significa "velho mestre”, mas sua biografia é um pouco questionável. A compilação mais antiga que apresenta as possíveis biografias de Laozi data da dinastia Han e foi feita por Sima Qian.

Nela, Sima Qian (apud LAOZI, 2016, p. XXXII) cita três pessoas que poderiam ser o Laozi histórico: um funcionário da biblioteca da corte de Zhou, mais velho que Confúcio, chamado Li Er; um outro, contemporâneo do Mestre, que compilou ideias taoistas, chamado de Lao Laizi; e o Cronista-Mor Dan, ativo cerca de um século após a morte do grande intelectual confuciano.

Cada uma das biografias suscita uma característica da obra de Laozi, de acordo com Sinedino (LAOZI, 2016, p. XXXIII), “em sua narrativa, o Grande Cronista [Sima Qian] fala de Li Er e dos Ritos; de Lao Laizi e das técnicas de longevidade; e do Cronista-Mor Dan e das técnicas esotéricas". Poceski (2013, p. 80) afirma que a obra de Laozi é vista como um clássico de filosofia e religião, devido a suas fortes conotações místicas. Mas também pode ser lido como uma obra política (como a obra de Confúcio), um ensaio de estratégia militar, ou guia para atingir a longevidade. É interessante notar que o taoismo é uma filosofia/ religião baseada em textos/escritos literários, e acredita-se que divindades celestiais teriam revelado a realidade e os mecanismos do Tao.

Por fim, explica-se que, dentre as principais características, o taoismo é baseado na crença da wúwéi (无为), ou seja, não-ação, sendo assim o bom governante é aquele que interfere o menos possível na vida de seus súditos; na crítica a uma sociedade movida por ritos; no incentivo de que as pessoas se afastem do mundo (lembrando que no confucionismo prega-se que as pessoas vivam em sociedade seguindo diversos ritos e tradições); e nas técnicas para alcançar a longevidade (diz-se que Laozi teria vivido cerca de duzentos anos), vários taoístas morreram envenenados procurando o elixir da eternidade, e as práticas de exercícios físicos como o tàijíquán (太极拳), ou tai chi chuan, são exemplos dessa busca pelo bem-estar e longevidade. De acordo com Poceski (2013, p. 121), o cânone de textos taoístas usado hoje foi compilado em 1445, na dinastia Ming, e reúne cerca de 1500 títulos.

\subsection{A arte da guerra chinesa}

Apesar de não fazer parte dos "Três Ensinamentos", uma obra que não poderia deixar de ser comentada é A Arte da Guerra de Sunzi (孙子兵法, Sūnž̌ Bīngfă), seja por sua influência no pensamento chinês, seja por sua rentabilidade editorial no ocidente. Durante o enfraquecimento da dinastia Zhou, houve um momento de tensão social e de guerra civil entre os estados que compunham a "confederação" na época. Se o clima social inspirou ideias em vários pensadores como Confúcio e Laozi, também inspirou ideias em estrategistas

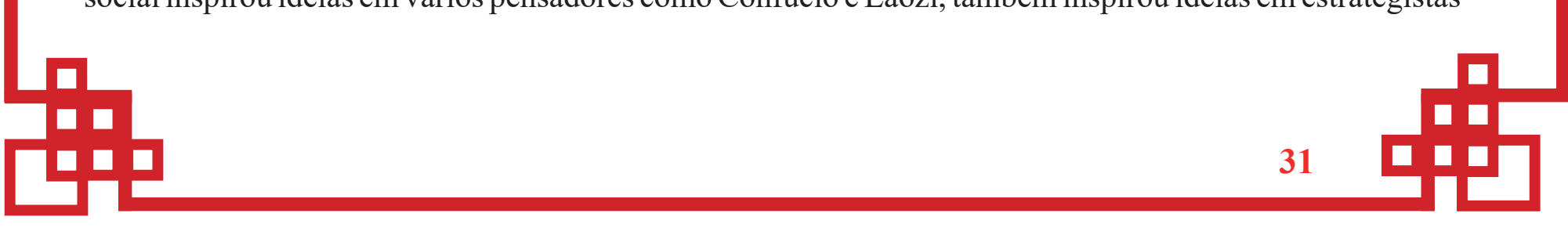


Zi Yue: revista de graduação de estudos sinológicos. São Paulo: Portal de Revistas da USP, v. 1, n. 1, 2020.

militares que precisavam ganhar as batalhas para seus governantes. Assim surge o tratado de Sunzi.

De acordo com Sun (2006), Sunzi teria nascido em 540 AEC no estado de Qi (região onde hoje se encontra a província de Shandong) e, em 517 AEC, teria saído de seu estado e ido para o estado de Wu (mais ao sul da China, englobando a região onde hoje se encontra Shanghai). Sawyer (2006) aponta que a posição oficial dele no exército é questionável, mas que se costuma aceitar que ele foi um estrategista, possivelmente tenha sido um general. Como prova de sua existência costuma ser apontada uma passagem dos Registros Históricos (史记, Shǐjì) de Sima Qian (historiador da China antiga já citado) na qual Sunzi, após falar de suas teorias ao rei, é desafiado a prová-las na prática. Para a demonstração, Sunzi solicita ao rei suas concubinas como cobaias, ele dá uma instrução militar a elas e , por elas zombarem dele não seguindo as ordens militares, ele manda decapitar as duas concubinas favoritas do rei, conseguindo a obediência militar das outras concubinas, provando sua capacidade de treinar um exército.

Com a popularização dessa obra no ocidente, há tradutores como Cleary (1998), o qual defende que A Arte da Guerra é um livro de inspiração taoísta com várias referências ao Dao De Jing e ao Livro das Mutações (duas obras chinesas igualmente populares no meio editorial). Entretanto, apesar de as obras e escolas chinesas de pensamento se interinfluenciarem, se for considerada a data atribuída ao nascimento de Sunzi, que é quase a mesma à atribuída a Confúcio, e partindo do pressuposto de que Confúcio geralmente é considerado mais velho do que Laozi, logo, a afirmação de que A Arte da Guerra pertence às obras taoístas é possivelmente muito forte e uma tática de vendas (como uma obra poderia ter várias referências ao Dao De Jing antes deste haver sido escrito?).

Observa-se ainda que a compilação e edição do Livro das Mutações é atribuída a Confúcio, e que tal livro inclusive faz parte do cânone confuciano. Ressalta-se também que A Arte da Guerra é um livro de estratégias militares, feita por um homem que trabalhava com a guerra em um contexto de guerra civil, embora se tente relacionar a ideia de "vencer uma guerra com o mínimo de esforço" de Sunzi, com a de não-ação de Laozi, talvez deva ser lembrado que Sunzi pensava num contexto de campo de batalha, enquanto Laozi pensava em como reestruturar uma sociedade em decadência.

É interessante notar ainda que tradicionalmente A Arte da Guerra possui treze capítulos, entretanto há edições recentes que dizem haver recuperado um décimo quarto capítulo perdido (um capítulo adicional). Além disso, com o sucesso da obra de Sunzi, uma obra atribuída a seu suposto neto Sun Pin ganhou evidência. Sawyer (2006) explica que embora Sun Pin seja considerado pela tradição como o neto de Sunzi, cem anos separam o nascimento dos dois, e que mais provavelmente eles tenham um 
parentesco de bisneto ou tataraneto. Há ainda possibilidade de eles serem apenas pessoas do mesmo clã.

\section{A ponte tradutológica entre a China e o ocidente}

Sobre o intercâmbio cultural ocidente e a China, o pesquisador Peter Buker (2009) apresenta dados importantes, como o fato de a Europa haver tido grande interesse na China, como demonstrado "pelas muitas traduções de Marco Polo, pela descrição da China feita pelo frade agostiniano Juan González de Mendoza, e pela história da queda da dinastia Ming escrita pelo jesuíta italiano Martino Martini” (BUKER; HSIA, 2009, p. 28). Esta última, por exemplo, “foi traduzida nove vezes. Graças a suas traduções para o holandês e o inglês, a obra de Martini foi usada como inspiração para obras de dramaturgia por Joost van Vondel (Zungchin, 1667) e Elkanah Settle (A conquista da China, 1676)” (Idem, p. 148). Segundo Hsia (2009, p. 47), a missão católica jesuíta na China foi estabelecida em 1583 por Michele Ruggieri e Matteo Ricci, tendo alcançado o apogeu aproximadamente em 1700. Destacam-se, nesse período, em torno de 450 obras compostas e publicadas em chinês pelos europeus. "Desse total, perto de 120 textos tratam da ciência, tecnologia e geografia europeias; outros 330 são textos religiosos” (Idem, p. 47).

Apesar do número surpreendente de obras vertidas ao chinês, Hsia (2009) afirma que apenas cinquenta e nove padres estavam envolvidos nas publicações, e as traduções foram feitas por apenas dezoito padres, dos quais oito eram italianos, cinco portugueses, três franceses e dois belgas (Idem, p. 53). Observa-se ainda que os jesuítas portugueses representaram a maior força de europeus em solo chinês durante o período de 1583 a 1723, contando com um total de 129 padres, entretanto, dos dezessete que publicaram textos, apenas cinco traduziram. Abrindo espaço para a dominação francesa no século XVIII. Contudo, com o fim da Companhia de Jesus o número de traduções já havia caído e a primeira edição dos clássicos chineses chega à Europa por tradutores belgas.

O segundo período, de 1680 à dissolução da Companhia de Jesus, foi caracterizado por uma queda significativa na produção de títulos chineses, pelo estreitamento dos temas (concentrando-se em obras catequizadoras e devocionais), por mais publicações na linguagem coloquial e pela tradução de um pequeno corpo de textos cristãos para o manchu, a língua da dinastia Qing. Também foi significativa nesse segundo período a transmissão de textos e da cultura chinesa para a Europa. Começando com a tradução dos Quatro Livros Confucianos (O grande ensinamento, A doutrina do meio, Os analectos e Mêncio), sob editoria do belga Philippe Couplet (Confucius, 1687), jesuítas franceses, alemães e austríacos continuaram a incrementar o corpus de Sinica ao longo do século XVIII. Se 1580-1680 foi o século europeu para a China, os cem anos seguintes representaram o século chinês para a Europa (Idem, pp. 54-55).

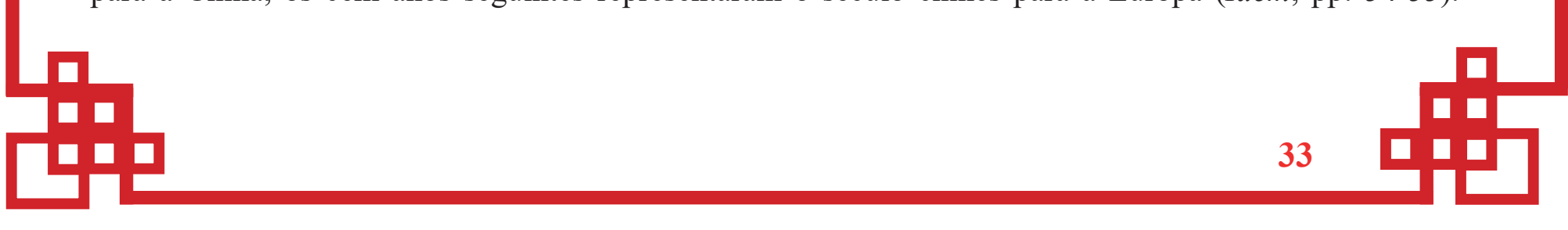


Os primeiros textos transmitidos da civilização chinesa que os ocidentais têm hoje são considerados o 书经 (Shūjīng), Livro dos Documentos (ou Livro da História); 诗经 (Shījīng), Livro das Canções; e o 易经 (Yìjīng), Livro das Mutações (Idem, p. 85). Desta forma, o cânone confuciano e a linguagem do final da dinastia Zhou foram mantidos pela dinastia Han criando a linguagem literária da China pelos dois mil anos seguintes, sendo os termos "chinês clássico" e "chinês literário" sinônimos (Idem, p. 87). Tais usos da língua ainda podem ser encontrados em prefácios de trabalhos acadêmicos e na poesia.

\section{As publicações de filosofia chinesa no Brasil dos séculos XX e XXI}

Serão apresentados aqui os dados quantitativos das obras de filosofia chinesa publicadas no Brasil durante os séculos XX e XXI até 2017, dividindo-se em quatro áreas:

1) livros que tratam de Confúcio; que são títulos (traduções) de autoria de Confúcio; ou que compõem o cânone confuciano, como a obra 易经 (Yìjīng, I ching ou O livro das mutações);

2) livros que tratam de Laozi; que são traduções das obras de Laozi; que tratam do taoismo ou que se debruçam sobre autores relacionados a Laozi, como Zhuangzi;

3) livros que tratam de Sunzi; que são traduções das obras de Sunzi; que tentam se relacionar com esse autor de alguma forma, como as atribuídas a um possível descendente de Sunzi, Sun Pin;

4) por fim, livros que não se encaixam nas definições acima e que versam sobre o pensamento chinês, asiático, podendo ser genericamente classificados como obras de "pensamento chinês", tendo essa categoria a particularidade de ser majoritariamente composta por autores vivos no momento da publicação de seus livros. Tendo em vista tais classificações, encontraram-se os seguintes resultados:

\begin{tabular}{|c|c|c|c|c|c|}
\hline \multicolumn{6}{|c|}{ Tabela 1- Publicações de filosofia chinesa separadas por data de primeira edição ${ }^{8}$} \\
\cline { 1 - 4 } "Escola" & Confucionismo ${ }^{9}$ & Taoismo & Sunzi & $\begin{array}{c}\text { Pensamento } \\
\text { Chinês }\end{array}$ & $\begin{array}{c}\text { TOTAL POR } \\
\text { PERÍODO }\end{array}$ \\
\cline { 1 - 5 } $\begin{array}{c}\text { Data da primei- } \\
\text { ra edição }\end{array}$ & 1 & 0 & 0 & 0 & 1 \\
\hline $\begin{array}{c}\text { Século XVI- } \\
\text { XVII }\end{array}$ & 1 & & & & \\
\hline
\end{tabular}

8 Observa-se que o foco da nossa pesquisa são os séculos XX e XXI e que as publicações de datas anteriores estão citadas apenas a título de curiosidade. Na coluna relativa às obras de Confúcio, tem-se a publicação de dois livros em Macau entre 1970-1989.

9 Descontando-se os quatro livros que não pertencem ao nosso foco de busca, o número total de obras confucianas é de 79 
Tabela 1- Publicações de filosofia chinesa separadas por data de primeira edição ${ }^{8}$

\begin{tabular}{|c|c|c|c|c|c|}
\hline $\begin{array}{c}\text { Século XVI- } \\
\text { II-XIX (1899) }\end{array}$ & 1 & 0 & 0 & 0 & 1 \\
\hline $1900-1929$ & 0 & 0 & 0 & 0 & 0 \\
\hline $1930-1949$ & 2 & 0 & 0 & 2 & 4 \\
\hline $1950-1969$ & 3 & 1 & 1 & 0 & 5 \\
\hline $1970-1989$ & 20 & 12 & 4 & 4 & 40 \\
\hline $1990-1999$ & 15 & 13 & 9 & 17 & 41 \\
\hline $2000-2005$ & 20 & 10 & 39 & 2 & 50 \\
\hline $2006-2010$ & 13 & 7 & 14 & 0 & 26 \\
\hline $2011-2017$ & 9 & 3 & 84 & 14 & -- \\
\hline $\begin{array}{c}\text { TOTAL POR } \\
\text { "ESCOLA": }\end{array}$ & 83 & 46 & 228 & & \\
\hline Total de obras ${ }^{10}:$ & & & & & \\
\hline
\end{tabular}

Tabela 2 - Obras publicadas por editoras

\begin{tabular}{|c|c|c|c|c|c|c|}
\hline Posição & Editora & TOTAL & Confucionismo & Taoismo & Sunzi & $\begin{array}{c}\text { Pensamento } \\
\text { chinês }\end{array}$ \\
\hline $1^{\text {o }}$ & Record & $\mathbf{1 6}$ & 4 & 4 & 7 & 1 \\
\hline $2^{\text {o }}$ & Pensamento & $\mathbf{1 2}$ & 7 & 3 & 2 & 0 \\
\hline $3^{\text {o }}$ & Cultrix & $\mathbf{9}$ & 3 & 4 & 1 & 1 \\
\hline $4^{\text {o }}$ & Madras & $\mathbf{9}$ & 4 & 1 & 4 & 0 \\
\hline $5^{\text {o }}$ & M. Books (Makron & $\mathbf{9}$ & 0 & 0 & 9 & 0 \\
\hline $6^{\text {o }}$ & Círculo do Livro & $\mathbf{6}$ & 3 & 3 & 0 & 0 \\
\hline $7^{\mathbf{0}}$ & Tecnoprint & $\mathbf{6}$ & 4 & 1 & 0 & 1 \\
\hline $8^{\text {o }}$ & Martins Fontes & $\mathbf{5}$ & 2 & 2 & 1 & 0 \\
\hline $9^{\text {o }}$ & Nova Era & $\mathbf{5}$ & 4 & 1 & 0 & 0 \\
\hline $10^{\text {o }}$ & Universo dos Livros & $\mathbf{5}$ & 1 & 0 & 4 & 0 \\
\hline
\end{tabular}

Descontando-se as quatro obras que não foram publicadas entre os séculos XX e XXI ou no Brasil, o total é 224. 


\begin{tabular}{|c|c|}
\hline \multicolumn{2}{|c|}{ Tabela 3 - Obras confucianas } \\
\hline Analectos & 8 \\
\hline Confúcio & 22 \\
\hline I ching & 51 \\
\hline Comentários inespecíficos & 2 \\
\hline
\end{tabular}

\begin{tabular}{|c|c|}
\hline \multicolumn{2}{|c|}{ Tabela 4 - Obras taoístas } \\
\hline Dao De Jing & 22 \\
\hline Laozi & 4 \\
\hline Tao & 13 \\
\hline Taoismo & 3 \\
\hline Zhuangzi & 4 \\
\hline
\end{tabular}

\begin{tabular}{|c|c|}
\hline \multicolumn{2}{|c|}{ Tabela 5 - Publicações sobre Sunzi } \\
\hline A arte da guerra & 40 \\
\hline $\begin{array}{c}\text { Comentários, análises, } \\
\text { obras inspiradas em }\end{array}$ & 44 \\
\hline
\end{tabular}

Dentro do catálogo notou-se uma variação considerável de edições que correspondem à mesma obra; e.g., o 易经 (Yijing, geralmente publicado como I ching) no qual pode ser encontrada a variação de uma versão com obras de setenta páginas (como a edição da Editora Rideel, 2009) e outra versão que alcança quinhentas e vinte e oito páginas (como a edição da Martins Fontes, 2007). Tal variação é existente também entre os títulos e a grafia dos nomes dos autores, como a obra Dao De Jing. Pode-se considerar que a "liberdade" de interpretação dos títulos tenha atendido mais a critérios comerciais do que a relação com 
a obra; e.g., A arte da guerra para empresas e negócios: configurações estratégicas (São Paulo: Saraiva, 2005), A arte da guerra para concursos (Rio de Janeiro: Campus, 2007), A arte da guerra, plus, Estratégia para gerentes de vendas: estratégia para gerenciar a força de vendas (São Paulo: M. Books, 2009). Destacam-se aqui as diferentes visões que existem entre os tradutores e, consequentemente, da posição deles em relação aos conteúdos traduzidos, como também se entende que é possível a leitura de tais textos, em conformidade com uma cosmovisão ocidental, de forma mais inclinada para a filosofia ou religião.

Analisando os dados encontrados, o primeiro elemento que se percebe é o fato de não haverem traduções de obras de filosofia chinesa até a década de 1930. A primeira que se pôde recolher foi A sabedoria de Confúcio (1938) publicada pela Livraria José Olympio Editora, é interessante notar que foi publicada numa coleção de textos orientais chamada Coleção Rubayat e que o texto consistia numa tradução de uma obra em inglês organizada por Lin Yutang; a segunda obra localizada apresenta o título de Philosophia de Confúcio (1939), foi feita por Inácio Raposo e publicada pela Companhia Brasil Editora. Lin Yutang também teve traduzidos os títulos $A$ Importância do Viver (Rio Grande do Sul: Globo, 1941) e A sabedoria da China e da Índia: uma antologia dos tesouros das duas grandes literaturas orientais (Rio de Janeiro: Pongetti, 1945).

Pode-se pensar que há uma relação entre a expansão do mercado editorial na década de 1930 e as publicações de filosofia chinesa. É observável que a Revolução de 1930 teve como consequências sociais a aceleração e a expansão do ensino secundário, fazendo com que este alcançasse, na década de 1940, o dobro de alunos até então: 170 mil, e, no final da Segunda Guerra, 250 mil (HALLEWELL, 2012, p. 408). Segundo Cândido (2006, p. 219) a década de 1930 “foi um eixo e um catalisador: um eixo em torno do qual girou de certo modo a cultura brasileira, catalisando elementos dispersos para dispô-los numa configuração nova", dentre os elementos que Cândido ainda destaca da Revolução de 1930 estão a difusão e "normalização" de aspirações e inovações dos movimentos de vanguarda da década de 1920 e um alargamento da participação em setores da cultura como o livro e o rádio, também foi importante a radicalização ideológica dos intelectuais, o que rendeu diversos debates e estudos na forma de livros. Nas palavras de Hallewell:

De um modo geral, os anos de 1920 foram um período de pouca significação para a história do comércio livreiro no Rio de Janeiro. Não se registrou nenhuma evolução real entre a morte de Francisco Alves, em 1917, e a Revolução de 1930. No entanto, a revolução constituiu um marco tão fundamental para esta nossa história - e, de fato, para a história do Brasil em geral - quanto a chegada da família real, em 1808, o foi para o país (HALLEWELL, 2012, pp. 462-463). 
Zi Yue: revista de graduação de estudos sinológicos. São Paulo: Portal de Revistas da USP, v. 1, n. 1, 2020.

Em números, o produto industrial brasileiro deu um salto de 50\% entre 1930-1937; tendo o crescimento da edição de livros, com base nos dados de São Paulo, um aumento de $600 \%$ entre 1930 1936 (Idem, pp. 464-465). O recorte feito entre 1950-1969 no nosso catálogo não apresenta dados muito significativos, mas o crescimento para quarenta obras publicadas entre 1970-1989, período que abrange tempos conturbados na ordem política (com fases de forte repressão, censura mais branda e abertura política) e econômica (com o "milagre econômico" e as diversas crises enfrentadas pelo país). Segundo Hallewell (2012, p. 629), “para a indústria e o comércio do livro, o resultado líquido das políticas do novo regime militar, no período de 1964-1973, foi uma notável expansão.”. A produção de primeiras edições de livros no Brasil na década de 1970 passou de 2981 em 1971 para 7680 em 1973, caindo para 4164 em 1974 (Idem, p 904). O crescimento da indústria segue nos últimos anos do século XX, atingindo 10871 primeiras edições de títulos em 1991 e 18305 títulos no ano de 2000, caindo a seguir para 13340 no ano de 2003 (Idem, p. 936).

\section{CONSIDERAÇÕES FINAIS}

Conforme foi observado, a essência do pensamento chinês é definida a partir dos três ensinamentos, que mesclam teoria filosófica e práticas religiosas, sendo interpretadas pelos ocidentais ora como obras filosóficas, ora como obras religiosas. Ao contrário do que ocorre no Ocidente com a busca de uma verdade única e suprema, na China os três ensinamentos conviveram harmonicamente sendo vistos como complementares, apesar de, por vezes, um ser a negação do outro. Nesse sentido, tais obras podem ser enquadradas na concepção ocidental de filosofia pela proximidade com o saber e o estudo do homem e seu mundo, sendo Confúcio e Laozi vistos como grandes sábios antigos e venerados por isso; mas também podem ser tomadas como textos religiosos por toda a codificação de ritos do confucionismo, e no caso do taoismo por sua visão esotérica do mundo.

O final do levantamento catalogou duzentos e vinte e cinco livros de pensamento chinês publicadas no Brasil durante os séculos XX e XXI. Observando quatro obras lançadas entre 1930- 1949; cinco entre 1950-1969; trinta e oito entre 1970-1989; quarenta e uma entre 1990-1999; 68 cinquenta entre 2000-2005; sessenta e uma entre 2006-2010; e, vinte e seis de 2011 até o presente momento. Oitenta desses títulos fazem parte do conjunto de textos confucionistas; quarenta e seis são obras taoístas (Laozi); oitenta e quatro tratam d'A Arte da Guerra, de Sunzi; e quinze produções de outros autores podem ser incluídas, genericamente, como livros de pensamento chinês, por não pertencerem a nenhum dos três grandes segmentos acima encontrados. Destaca-se ainda que tais publicações foram 
publicadas por cento e quatorze casas editoriais, em especial as editoras Record e Pensamento, a primeira editou dezesseis obras, e a segunda, doze; além de Cultrix, Madras e M. Books, com nove livros cada.

Dentre as conclusões (ainda parciais) que podem ser obtidas a partir dos resultados encontrados, tem-se o fato de as publicações de pensamento chinês no Brasil terem seguido as tendências de expansão do mercado editorial brasileiro. Se a primeira obra encontrada data de 1938 (trata-se de um livro lançado pela Livraria José Olympio Editora), ao longo dos vinte anos seguintes, houve apenas quatro obras publicadas. Durante os anos da ditadura militar e reabertura assim como houve um forte crescimento do mercado editorial, também se detectou um aumento expressivo da publicação de obras de filosofia chinesa: passou-se de cinco para quarenta títulos ao longo do intervalo entre 1950 e 1989. Já entre 2006 e 2010, tem-se o auge da edição no Brasil de títulos de filosofia chinesa, quando houve sessenta e uma obras publicadas, com destaque para as trinta e nove edições de A Arte da Guerra, de Sunzi, livro que apresenta o maior total de publicações (oitenta e quatro). Assim nota-se a expansão, a partir dos anos 2000, do interesse em filosofia chinesa, com um especial modismo pela obra de Sunzi.

Destaca-se ainda que as publicações confucionistas, entre os anos de 1970 a 1989, quando a maior parte das obras de filosofia chinesa lançadas pertencia a esse segmento (vinte obras) contra doze obras taoístas e quatro de Sunzi, foram fortemente infladas pelas diferentes publicações do livro I ching que correspondem a 51 de 83 obras editadas em tal período. Tal fato demonstra o interesse maior do mercado pelo que possa ser vendido como religião chinesa ou esoterismo. Em tempos recentes, as trinta e nove publicações de A Arte da Guerra em seis anos (2005-2010) podem ser explicadas pelo interesse na economia chinesa e aprendizagem das técnicas de liderança que a obra de Sunzi pode proporcionar.

Em termos editoriais, pode-se entender o investimento da principal editora de obras de filosofia chinesa, a Record, devido ao tamanho de seu mercado e sua busca por publicar livros de sucesso; sua edição de $A$ arte da guerra superou quarenta reedições desde sua primeira publicação na década de 1980. Quanto à editora Pensamento, observa-se seu interesse em publicar ocultismo e espiritualismo, inferindo-se assim o viés editorial que as obras chinesas ganham nessa casa. A subsidiária da editora Pensamento, a editora Cultrix, não parece ter um viés claro de editoração que direcione a publicação de suas obras ao contrário da editora Madras e da M. Books: a primeira tem um interesse por obras "holísticas" e espirituais, e a segunda apresenta um claro viés administrativo/econômico. 


\section{REFERÊNCIAS BIBLIOGRÁFICAS}

ABI-SÂMARA, Raquel \& SCHMALTZ, Márcia. "Tradução de poesia entre português e chinês: pesquisa e catalogação historiográfica na Universidade de Macau”. In: SCHMALTZ, Márcia (org.). Cadernos de literatura em tradução, 14. São Paulo: FFLCH/Universidade de São Paulo, 2013, pp. 49-60. ARAÚJO, Emanuel. A construção do livro: princípios e técnicas de editoração. Rio de Janeiro:Nova Fronteira; Brasília: INL - Instituto Nacional do Livro,1995.

BUENO, André. “As dificuldades de Tradução: um ensaio sobre o Sunzi bingfa 孙子兵法e o contexto cultural brasileiro". In: Schmaltz, Márcia (org.). Cadernos de literatura em tradução, 14. São Paulo: FFLCH, Universidade de São Paulo, 2013, pp. 89-98.

BURKE, Peter; HSIA, R. Po-chia (orgs.). A tradução cultural nos primórdios da Europa Moderna. [Tradução Roger Maioli dos Santos] São Paulo: Editora UNESP, 2009.

CHENG, Tsung Jye. O pensador-ativista Mozi (c.470- c.390 a.C.): seu pacifismo comunitário radical. 2008. f. 253. Tese (livre-docência) - Faculdade de Filosofia, Letras e Ciências Humanas, Universidade de São Paulo, São Paulo, 2008.

CHANG, CHI-YUN. Chinese history of fifty centuries. Taipei: Institute for Advanced Chinese Studies, 1962, V.1.

CHANG, Kwang-Chih. China on the eve of the historical period. In: LOEWE, Michael; SHAUGHNESSY, Edward L. The Cambridge History of ancient China: From the Origins of Civilization to 221 B.C.. Cambridge: Cambridge University Press, 2007, p. 37-73. CLEARY, Thomas. Introdução: o taoismo e A Arte da Guerra. IN: SUNTZU. A Arte da Guerra. 10.ed. São Paulo: Pensamento, 1998, p. 9-25.

CONFÚCIO. Os analectos. Tradução para o inglês de Simon Leys [tradução para o português de Claudia Berliner]. São Paulo: Martins Fontes, 2005. Os analectos. Tradução comentários e notas de Giorgio Sinedino. São Paulo: Editora Unesp, 2012.

. Os analectos. Tradução comentários e notas de Giorgio Sinedino. São Paulo: Folha de São Paulo, 2015. 
D’HULST, Lieven. "Why and how to write translation histories”. In: MILTON, John (org.). Crop, vol. 6, Número especial: Emerging Wiews on Translation History in Brazil, 2001, pp. 21-32. Disponível em: $<$ http://200.144.182.130/revistacrop/ images/stories/edicao6/v06a03.pdf>. Acesso em 17 maio 2016. GENETTE, Gerárd. Paratextos editoriais. [Tradução de Álvaro Faleiros]. São Paulo: Ateliê Editorial, 2009.

HALLEWELL, Laurence. Olivro no Brasil: sua história. Trad. de Maria da Penha Villalobos, Lólio Lourenço de Oliveira e Geraldo Gerson de Souza. 3.ed. São Paulo: Editora da Universidade de São Paulo, 2012. LAOZI. Dao De Jing. Tradução comentários e notas de Giorgio Sinedino. São Paulo: Editora Unesp, 2016.

MENEZES JR., Antônio; CHEN, Tsung Jye. Introdução. In: SUN TZU. A arte da guerra. [tradução Elvira Vigna] São Paulo: Ediouro, 2009, p.15-41.

MILTON, John. O poder da tradução. São Paulo: Ars Poetica, 1993.

NIVISION, David Shepherd. The Classical Philosophical Writings. In: LOEWE, Michael; SHAUGHnessy, Edward L.. The Cambridge History of ancient China: From the Origins of Civilization to 221 B.C.. Cambridge: Cambridge University Press, 2007, p. 745-812. PAES, José Paulo. Tradução uma ponte necessária: aspectos e problemas da arte de traduzir. São Paulo: Ed. Ática, 1990.

POCESKI, Mario. Introdução às religiões chinesas. Tradução de Márcia Epstein. São Paulo: Editora Unesp, 2013.

RÓNAI, Paulo. A tradução vivida. 2.ed. Rio de Janeiro: Nova Fronteira, 1981.

Escola de tradutores. 4.ed. Rio de Janeiro: Educom, 1976.

SUN, Adam. Apresentação. IN: SUNZI. A arte da Guerra. São Paulo: Conrad Editora do Brasil, 2006, p.7-11.

Senhor da Guerra. IN: SUNZI. A arte da Guerra. São Paulo: Conrad Editora do Brasil, 2006, p.13-16.

SUNZI. A arte da Guerra. São Paulo: Conrad Editora do Brasil, 2006

SAWYER, Ralph D. Sawyer. Prefácio à edição americana. IN: SUN-TZU; SUN-PIN. A arte da Guerra. São Paulo: Martins Fontes, 2006, p. X-XV. . Introdução. IN: SUN-TZU; SUN-PIN. A arte da Guerra. São Paulo: Martins Fontes, 2006, p.149. 